\title{
METHODS FOR RETROSPECTIVE ASSESSMENT OF AN UNUSUAL BEHAVIOR OF A PERSON WITH DIABETES: EBRIETAS ALCOHOLICA AND/OR HYPOGLYCAEMIA?
}

\author{
Rudolf Chlup ${ }^{\mathrm{a}^{*}}$, Lubomír Neoral ${ }^{\dagger \mathrm{b}}$ \\ a Institute of Physiology and II ${ }^{\text {nd }}$ Department of Medicine, Palacký University \& Teaching Hospital, 77520 Olomouc, Czech \\ Republic; e-mail: rudolf.chlup@fnol.cz \\ ${ }^{b}$ Institute of Forensic Medicine, Palacký University, Olomouc
}

Received: May 2, 2004; Accepted: June 23, 2004

Key words: Diabetes mellitus/Insulin/Alcohol/Hypoglycaemia/Drunkenness/Accident

Short version presented at the 17th International Diabetes Federation Congress, Mexico City, Mexico, November 5-10, 2000

Drunkenness and/or hypoglycaemia are possible causes of unusual behavior in a person with diabetes. The aim of this study was to demonstrate different methods which were used in two contradictory reviews of experts for retrospective assessment of a patient's condition in the course of a car crash: An insulin-treated driver caused a car accident resulting in injuries to two men. He was accused of the crime of damage to health as well as of driving under the influence of an addictive drug. One expert, having seen the police and medical reports, concluded the driver was influenced by alcohol at the time of the accident. The contradictory argument of another expert, based on his own thorough investigation including selfmonitoring and completed by a model experiment, resulted in the conclusion that the driver was probably influenced by hypoglycaemia. Thus, the methods of the second expert seem to be useful reasonable tools to assess the unusual behavior of a person with diabetes.

\section{INTRODUCTION}

Under various circumstances it is questionable whether unusual behavior has been caused by drunkenness or hypoglycaemia, particularly if it is concerning a person with diabetes (Fig. 1). Experts often prefer drunkenness to explain all suggestive symptoms, even without having found any clear evidence of it.

\section{AIMS}

The aim of this paper is to demonstrate two contradictory expert reviews, which were important for the purpose of a forensic evaluation of a car crash and, in addition

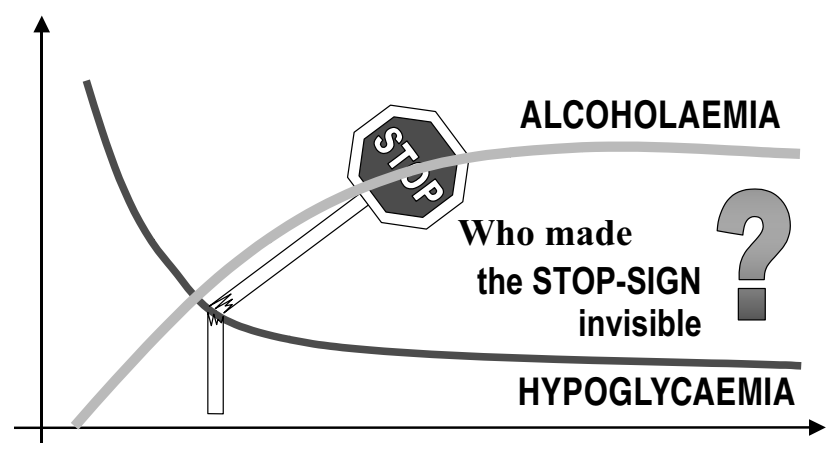

Fig. 1. Principal question to be answered by experts retrospectively. to traditional evaluation of police records, to test and recommend other reasonable methods for retrospective assessment of the unusual behaviour.

\section{MATERIAL AND METHODS}

Description of the accident and the Report of the first expert are taken from police and medical reports. All items are shortened and adapted because the original documents contain too much redundant information.

The second expert is one of the authors of this paper and his Report contains the detailed description and assessment of three additional methods tested: 1 . the investigation of the accused driver performed by the expert, 2. the evaluation of the data in the personal glucometer of the accused driver, 3 . the performance of the model experiment.

\section{RESULTS}

\section{Description of the accident}

Car driver X (aged 43, type 1 diabetes mellitus since 29 year of age) when entering onto a main road did not respect the traffic sign "STOP! Yield Way!" and collided with another car travelling on the main road. X suffered head and hand injuries. Driver Y, who was travelling on the main road, suffered a fracture of his right radius. His 
passenger $\mathrm{Z}$ was not injured. $\mathrm{X}$ was accused of the crime of damage to health under regulation 223 of the Czech criminal law and, based on the following investigation and the review of an expert, as well as of the crime of driving under the influence of an addictive drug (alcohol) according to regulation 201 of the criminal law 5 .

\section{Witness statements}

Injured driver Y: Immediately after the crash, the driver-culprit seemed to have fallen asleep with his head on the steering wheel. Within five minutes he woke up and became aggressive. I recognized he was absolutely drunk and unable to function normally. He was nasty, abusive, offended everybody, and said we had been trying to kill him and to take his money.

Passenger Z: The driver-culprit, after becoming conscious, attempted to insult me. His drunkenness could be recognized from the smell of alcohol on his breath, as well as his poor pronunciation and behaviour. He was moving with unsure steps and was very aggressive.

Police officer: Driver X had the smell of alcohol on his breath. However, he insisted on not having drunk anything. He did not mention he was a diabetic. It could be seen he was not cognisant, probably because of alcohol.

Another witness - owner of a nearby car service station: After the crash, the driver X seemed to be normal, he was just somewhat tired and stressed. He was neither drunken nor aggressive and I did not see him drinking previously.

Physician on call (from the first aid ambulance): Driver $\mathrm{X}$ was bleeding from the face. He was drunken, vulgar, rejected any help, and tried to remove the dressings from his wounds. He was making threats and he did not want to co-operate. He said he was a diabetic treated with insulin three times a day. In the course of my 20 years of practice I have faced the problem of distinguishing symptoms of drunkenness and hypoglycaemia several times. I suppose I am able to distinguish these two conditions. The estimation of blood glucose was made impossible by the negative attitude of the patient. The possibility of poor diabetes control might be excluded by the fact that the patient's condition did not become worse during the stay at the surgical out-patient department in the hospital. The patient's condition was induced by alcohol consumption as the patient was noisy and vulgar and pushed away the physician.

\section{Accused driver's (X) statement}

I have been driving since I was 18 year old. I have driven about $150,000 \mathrm{~km}$. I am a diabetic on insulin. On the day of the accident I injected my last dose of insulin at midday. At about $15.30 \mathrm{hr}$ I drank half a pint of dia-beer (special beer for diabetic patients - Ed) without eating anything. At about $20.00 \mathrm{hr}$, when I was returning by car from a local auto service station, I felt weak. I was confident of overcoming my weakness since I had only $150 \mathrm{~m}$ to travel to my home. When entering the main road I collided with another car and suffered injuries and damaged both cars. Nobody asked me to take a blood test or blow into a balloon. I refused to let them take blood in the hospital since I could not see any reason for it. After the crash I had not eaten sugar nor injected any insulin. I might have had a bad smell of alcohol since I had been transporting a basket of 29 bottles of slivovice (plum brandy) in the luggage compartment of my car, and 17 of them were destroyed due to the car crash.

\section{Methods and conclusions of two experts \\ A) Report of the first expert}

The first expert based his conclusions on the police and medical reports as follows:

- The signs of drunkenness in driver X were impossible to be mistaken for symptoms of an acute diabetic attack. The described condition (ie behavior of the accused) could be induced by drinking alcohol and it is almost certain that alcohol was the cause. The behaviour of the accused would correspond to a middle degree of drunkenness, ie 1.0 to 2.0 promille $(0.001$ - 0.002) alcohol in blood.

- Hypoglycaemia may be similar to other neurological and psychiatric conditions including drunkenness and sometimes it is difficult to distinguish between them. The physician on call concluded clearly that the accused exhibited typical signs of drunkenness, which could not be provoked by hypoglycaemia. As an expert I tend to accept this medical conclusion and believe the behaviour of the accused driver corresponded with a condition of drunkenness and not diabetic coma. Both hypo- and hyperglycaemia should be treated immediately to prevent unconsciousness and a lifethreatening situation.

As the accused driver did not agree with the charge of drunkenness, the police asked for the opinion of another independent expert.

\section{B) Report of the second expert}

The second expert based his report on not only the police protocol including previous medical reports, but also on his own investigations including the evaluation of blood glucose values in the memory of patient's personal glucometer, and on a model experiment.

\section{Summary of medical examination}

Diagnosis: Insulin-dependent diabetes mellitus since 29 th year of age, complicated by incipient retinopathy, sensomotor polyneuropathy and hypertension. In the course of the last year there were no changes in insulin doses: Actrapid MC 12-10-10 IU and Ultralente MC at 20.00 hr 30 IU. In the course of the year before the accident, his body weight increased from 92 to $94 \mathrm{~kg}$.

\section{Condition of driver $\mathrm{X}$ during hospitalisation 10 month after the crash}

Physical examination: Pulse rate 80/min, BP 140/105 $\mathrm{mmHg} . .120 / 80 \mathrm{mmHg}$, body weight $99.0 \mathrm{~kg}$, height $187 \mathrm{~cm}$. Constitution mesomorph, incipient paradentosis, tonsils red. Hyporeflexia. No other abnormalities. 
Laboratory investigations: HbA1c 8.3 (norm < 6.4 \%), cholesterol 5.63, GMT 0.97.

Normal findings: urine, FW, blood count, ECG, Chest X-ray, sonography of the abdomen. Serum: urea, creatinine, $\mathrm{Na}, \mathrm{K}, \mathrm{Ca}, \mathrm{Mg}, \mathrm{Cl}, \mathrm{AST}, \mathrm{LDH}, \mathrm{ALT}, \mathrm{ALP}$, uric acid, albumin, triacylglycerols, total protein. renal function tests were all normal. Blood glucose profiles see Table 1.

\section{Evaluation of data from the patients personal glucometer}

Glycaemia ranging from 2.6 to $17.4 \mathrm{mmol} / \mathrm{L}$, values $<3 \mathrm{mmol} / \mathrm{L}$ have always been found in the late afternoon.
During the six weeks prior to the accident, $\mathrm{X}$ performed 27 blood glucose estimations by means of his personal Glucometer One Touch II and three hypoglycaemic values ( $11 \%)$ were found in the late afternoon. After the accident, 17 out of 154 values ( $11 \%$ ) were below $3.0 \mathrm{mmol} / \mathrm{L}$.

\section{Model experiment}

In order to evaluate the influence of alcohol on diabetes control a model experiment was carried out (Table 2). In this experiment, the general conditions of insulin administration, food intake and drinking the dia-beer were made similar to the day of the accident. Alcohol was estimated on a Perkin Elmer GC 45 Multifract analyzer.

Table 1. Glycaemia (mmol/L) and insulin (kind and doses) on two consecutive days in hospital.

\begin{tabular}{|c|c|c|c|c|c|c|c|c|c|c|c|c|}
\hline Day & Actrapid & Ult. & $6: 00$ & $9: 00$ & $12: 0$ & $15: 0$ & $17: 3$ & $20: 30$ & $22: 00$ & $0: 30$ & $2: 30$ & $6: 00$ \\
\hline 1 & $10-8-8$ & 30 & 4.2 & 13.0 & 9.6 & - & 3.5 & $\mathbf{2 . 8}$ & $\mathbf{3 . 0}$ & $\mathbf{2 . 2}$ & $\mathbf{2 . 9}$ & $\mathbf{3 . 0}$ \\
\hline 2 & $10-8-8$ & 30 & 3.0 & 16.4 & 10.5 & 8.7 & 9.9 & 12.9 & 11.2 & 9.2 & 13.9 & 14.5 \\
\hline
\end{tabular}

The daily insulin dose was 8 IU smaller then on the day of the accident. Ult. - insulin Ultralente

Table 2. Schedule and results of the model experiment with driver X.

\begin{tabular}{|c|c|c|c|c|c|}
\hline Day & Time & Insulín [IU] & Food and drinks & $\begin{array}{l}\text { Alcohol in } \\
\text { blood }\end{array}$ & $\begin{array}{l}\text { Glycaemia } \\
\text { [mmol/L] }\end{array}$ \\
\hline \multirow[t]{2}{*}{ previous } & $20: 00$ & $\begin{array}{c}\text { Actrapid MC } 8 \\
\text { Ultralente MC } 32\end{array}$ & bread, butter, salami, tea & - & - \\
\hline & $22: 00$ & 0 & banana & - & - \\
\hline \multirow[t]{11}{*}{ test day } & 6.30 & Actrapid MC 12 & coffee with milk, bread, butter, jam, orange & - & 2.4 \\
\hline & $9: 45$ & 0 & bread, milk & - & 8.8 \\
\hline & $12: 30$ & Actrapid MC 10 & vegetable soup, potatoes, meat, tomato salad & - & 4.5 \\
\hline & $15: 00$ & 0 & bread (small slice), coffee with milk & - & 1.8 \\
\hline & $15: 20$ & 0 & & 0 & 5.9 \\
\hline & $15: 25$ & 0 & dia-beer $(300 \mathrm{ml}=10 \mathrm{~g}$ alcohol $)$ & - & - \\
\hline & $16: 30$ & 0 & 0 & 0 & 5.2 \\
\hline & $17: 30$ & 0 & 0 & 0 & 4.4 \\
\hline & $18: 30$ & 0 & 0 & 0 & $4.1(4.3)$ \\
\hline & $20: 00$ & 0 & 0 & 0 & 4.1 \\
\hline & 20:05 & Actrapid MC 8 & bread, butter, cheese, tea & - & - \\
\hline
\end{tabular}

\section{Core of questions given to the second expert}

1. Was the insulin treatment adequate at time of the crash?

2. What are the symptoms and causes of hypoglycaemia and how is it possible to distinguish hypoglycaemia from drunkenness?

3. How could diabetes be influenced by alcohol intake?

4. Does the behaviour of the accused driver at the time of the accident either support the assumption that his illness was serious or that his compliance was bad or the described condition could be caused by his alcohol intake?

5. Could the health condition of the accused driver and/or alcohol intake restrict his abilities to control himself, to recognize what was going on, and to drive a motor vehicle?

\section{Conclusions of the second expert}

1. Repeated hypoglycaemias and the increase in body weight (from 92 to $94 \mathrm{~kg}$ ) in the course of the last year before the accident suggest that the insulin treatment was not adequate, ie the unnecessarily large insulin dose (62 IU/day) resulted in an increased risk of hypoglycaemia (Fig. 2).

2. Among the first symptoms of hypoglycaemia to appear are disturbed concentration, tiredness, sleepiness, nervousness, aggressiveness, and negativism (ie the rejection of all recomendations including first aid in 


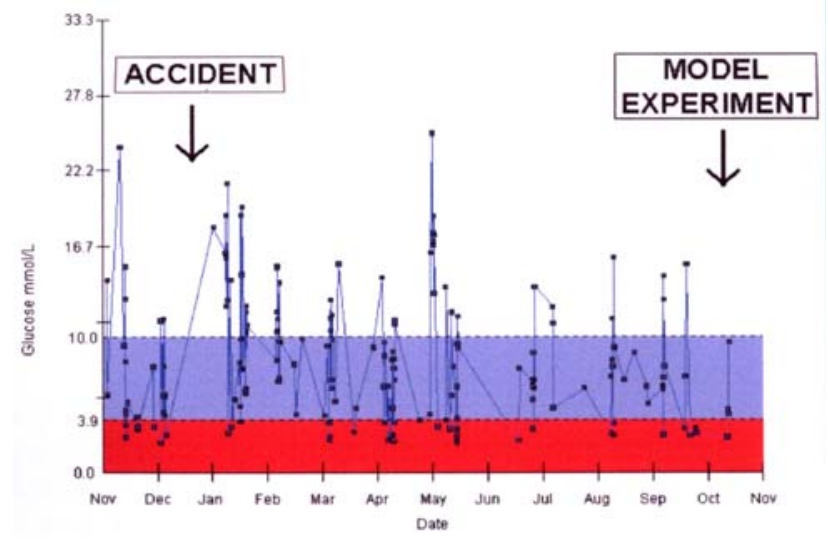

Fig. 2. Glycaemias 6 weeks before and 40 weeks after the accident (from the memory of patient's personal glucose meter One Touch II): $22 \%$ of all values were below the lower border of target $(<3.9 \mathrm{mmol} / \mathrm{L})$.

the event of an accident, blood testing etc). A hypoglycaemic reaction is usually accompanied by sweating, disorientation, confusion and, in an advanced state, also by cramps and unconsciousness which may result in death. Hypoglycaemia may be caused by too large insulin dose and/or limited food intake and/or greater physical exercise than usual, and may also be provoked by consumption of alcohol. Hypoglycaemia may last several minutes or several hours, until it is interrupted by adequate treatment. Sometimes, a spontaneous recovery may occur. The symptoms of hypoglycaemia are identical with symptoms of drunkenness (ethylalcohol intoxication), so that it is impossible to distinguish these two conditions without estimation of blood or urine alcohol concentrations as well as blood glucose concentrations ${ }^{2}$.

3. In an insulin-treated diabetic patient alcohol may induce either hypoglycaemia or hyperglycaemia ${ }^{3}$. If alcohol intake is preceded by starvation or muscular exercise there is a tendency to hypoglycaemia which may occur as late as several hours afterwards. That is why the model experiment for driver $\mathrm{X}$ was necessary, showing no alcohol in four blood tests performed at 60 to 90 minutes intervals after the drinking of diabeer (the peak of concentration was probably missed); however, his glycaemia decreased from $5.9 \mathrm{mmol} / \mathrm{L}$ at $15.20 \mathrm{hr}$ to $4.1 \mathrm{mmol} / \mathrm{L}$ at $20.00 \mathrm{hr}$.

4. The patient's behavior in hypoglycaemia may have the same features as the behaviour of a drunken (ethylalcohol intoxicated) person ${ }^{2}$. Hence, all witness' statements describing the driver $\mathrm{X}$ as "being drunken”, without bringing any evidence of alcohol concentration in his blood or at least indirect proof of drinking alcohol, support the presumption that $\mathrm{X}$, at the time of the accident, really suffered from hypoglycaemia. Moreover, this presumption is supported by the fact that several hypoglycaemias in the daytime corresponding to the time of day of the accident, were registered on other days (Fig. 3). The unambiguous

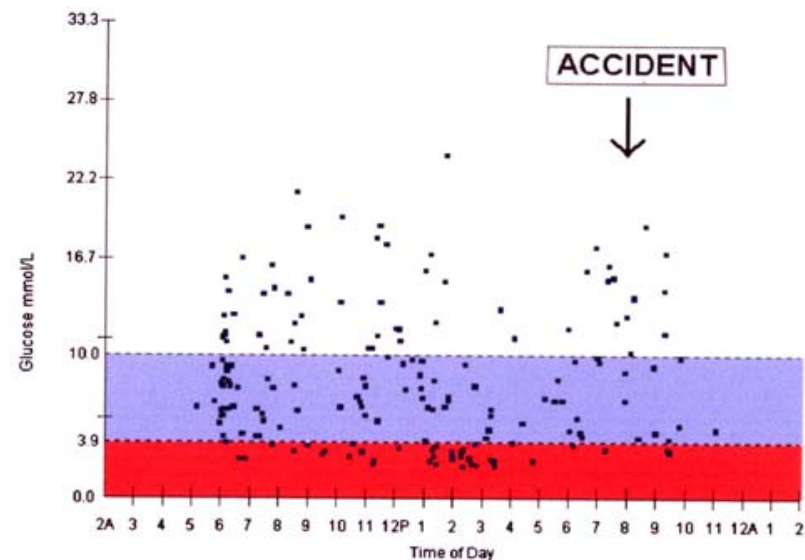

Fig. 3. Modal day: values of glycaemias from Fig. 2 transferred into one day.

conclusion that the patient's condition was caused by a hypoglycaemic reaction, would need an estimation of glycaemia right at the time of the crash; however, this was not carried out. The intake of alcohol is not forbidden in diabetic patients, therefore drinking $300 \mathrm{ml}$ of beer on the day of the accident was not a sign of the patient's poor compliance.

5. The driver's restricted abilities to control himself, to recognize what was going on and to drive a motor vehicle could have been due to either hypoglycaemia without alcohol intoxication, or drunkenness without hypoglycaemia, or hypoglycaemia induced by a small amount of alcohol.

\section{DISCUSSION}

In the described case, the opinions of lay witnesses are understandable. The approach of the physician on call and of the first expert seem to be derived from the fact that in our population the frequency of drunkenness prevails over the frequency of hypoglycaemic reactions. It is surprising that both the above said specialists, after having emphasised that drunkenness and hypoglycaemia are difficult to distinguish, made their unambiguous conclusions based on their imaginary 'experience' that the driver's condition in this particular case was induced by alcohol.

On the other hand, the authors of this paper (one of them being the second expert) believe the outcomes of a personal patient's investigation and of a model experiment may support more logical and more reasonable conclusions. It is, of course, impossible to produce evidence that the driver $\mathrm{X}$ was not drunk; however, from the point of view of medical ethics, it seems to be more reasonable to think first about medical causes of any patient's condition when the cause is unclear, and to treat him as a sick human being, ie in all cases of apparent drunkenness, hypoglycaemia should be assumed and treated even though 
ebrietas alcoholica and/or hypoglycaemia?

there may be no information available on blood glucose and alcohol concentrations. Additionally, in persons without diabetes, other possible causes of hypoglycaemia shoud be taken into consideration ${ }^{4}$.

\section{CONCLUSION}

For the retrospective assessment of the unusual behavior of a person with diabetes three additional methods are recommended: 1 . a thorough clinical investigation carried out by the expert, 2. the evaluation of person's data from his/her personal glucometer, and 3. the model experiment.

\section{REFERENCES}

1. Chlup R, Neoral L. (2000) Contradictory Reviews of Experts to Assess Drunkenness and/or Hypoglycaemia in a Type 1 Diabetic Driver. Diab Res Clin Pract 50 Suppl 1, S236-S237 (Abstract).

2. Neoral L, Chlup R. (1998) Unusual interaction of human behaviour, influenced by alcohol and disease, from the point of legal responsibility. In: Proceedings, $12^{\text {th }}$ World Congress on Medical Law, Siófok, 2, 486-489.

3. Neoral L, Chlup R, Loyková V, Franková M, Zedníková K, Bartek J, Mazochová J. (1991) Vliv inzulinu na metabolismus etylakoholu a vliv etylalkoholu na glykemii u diabetiků 1. typu. Protialkoholický obzor 26, 329-337.

4. Škrha J. (1999) Nondiabetic hypoglycemia and organic hyperinsulinism. Diab Met Endokrin Výž 2, 81-85.

5. Zákon č. 140/1961 Sb. ve znění pozdějších předpisů. 